leakage or prolonged respiratory support was observed nor did major bleeding, mediastinitis or empyema occur.

\section{Discussion \\ The slitting of the left upper pulmonary lobe is an easy and effective method to avoid traction to the LITA conduit and is also applicable in off-pump surgery. To arrest the ventilation during the procedure is a very useful trick, first to simplify the positioning and second to avoid injury of the inflated lung with the tip of the stapler. This technique is also applicable on the right side, but until now, we have no experience as to how much graft length we could gain with a slit right lung. The main advantage of this technique is the straight,tension-free position- ing of the graft without kinking. Furthermore, in case of a redo procedure, the LITA graft is protected underneath the lung and is far away from the track of the sternotomy. However, a disadvantage is represented by the costs in connection with the single-used disposable device. The costs for the device and the clip suture amount to approximately $\$ 250$ US. A possible pitfall}

might be in patients with multiple apical bullae. A single slit could result in persisting air leaks caused by the possibility of torn tissue. If the patient fulfills the criteria of lung volume reduction surgery, a more extended procedure with resection of the upper segments or a bullectomy could be performed.

\section{References}

1. Cameron A, David KB, Green G, Schaff HV. Coronary bypass surgery with internal thoracic artery grafts-effects on survival over a 15-year period. N Engl J Med. 1996;334:216-9.

2. Hirotani T, Nakamichi T, Munakata M, Takeuchi S. Risks and benefits of bilateral internal thoracic artery grafting in diabetic patients. Ann Thorac Surg. 2003;76:2017-20.

3. Gaudino M, Toesca A, Nori SL, Glieca F, Possati G. Effect of skeletonization of the internal thoracic artery on vessel wall integrity. Ann Thorac Surg. 1999;68:1623-7.

4. Del Campo C. Pedicled or skeletonized? A review of the internal thoracic artery graft. Tex Heart Inst. 2003;30:170-5.

5. Rao P, Natarajan K, Morritt G. "LIMA fissure" for a tension-free IMA graft in emphysema. Ann Thorac Surg. 1997;63:561-2.

\title{
Closure of ventricular septal defects in the donor heart before transplantation: Toward expanded acceptance criteria
}

\author{
S. Maltais, MD, MSc, ${ }^{a, b, c}$ M. Carrier, MD, ${ }^{a, b, c}$ M. Pellerin, $M D^{a, b, c}$ and \\ L. P. Perrault, MD, PhD, a,b,c Montreal, Quebec, Canada
}

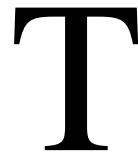

he limited supply and increasing shortage of adequate donor organs for transplantation has been met with expansion of criteria for donor heart acceptance. ${ }^{1}$

Patent foramen ovale and atrial septal defects have been diagnosed after cardiac transplantations $s^{2,3}$ and have been treated by surgical or transcatheter closure. ${ }^{4}$ Occasionally, significant rightto-left shunting across a septal patent foramen ovale might result in profound hypoxemia. Residual atrial defects might cause a serious hemodynamic compromise because of shunting and significant tricuspid regurgitation. ${ }^{3}$ The present report describes 2 successful

From the Research Center and the Department of Surgery, ${ }^{\mathrm{b}}$ Montreal Heart Institute, and the University of Montreal, ${ }^{\mathrm{c}}$ Montreal, Quebec, Canada.

Received for publication Aug 30, 2004; accepted for publication Sept 7, 2004.

Address for reprints: L. P. Perrault, MD, PhD, Research Center, Montreal Heart Institute, 5000 Belanger St East, Montreal, Quebec, H1T 1C8 Canada (E-mail: louis.perrault@icm-mhi.org).

J Thorac Cardiovasc Surg 2005;129:1187-8

$0022-5223 / \$ 30.00$

Copyright $\odot 2005$ by The American Association for Thoracic Surgery

doi:10.1016/j.jtcvs.2004.09.030 heart transplantations after concomitant surgical closure of a ventricular septal defect (VSD) in the donor heart.

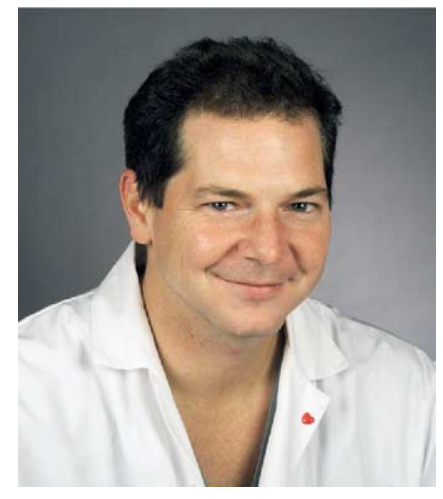

Dr Perrault

\section{Clinical Summary}

PATIENT 1. A 41-year-old man with no medical history was given a diagnosis of brain death after self-inflicted head trauma, and consent was obtained for multiple organ donation.

The preharvesting transthoracic echocardiogram revealed a small, 4-mm, restrictive perimembranous VSD with a normal ejection fraction and normal heart valves. Hemodynamic parameters were completely normal without need for pharmacologic support.

A compatible 58-year-old male recipient with terminal idiopathic dilated cardiomyopathy was identified at our institution.

The donor heart was explanted through a median sternotomy, and cardiac arrest was induced with $1 \mathrm{~L}$ of Celsior solution (Sangstat, Montreal, Quebec, Canada) at $4{ }^{\circ} \mathrm{C}$ along with surface cooling. Before transplantation, the VSD was repaired on the back table through a 4-cm right anterior ventriculotomy. Two interrupted polypropylene 4-0 sutures were used for closure of the defect (Figure 1, A). A standard orthotopic heart transplantation with biatrial anastomotic implantation (Stanford technique) was then performed with an ischemic time of 106 minutes. The pa- 

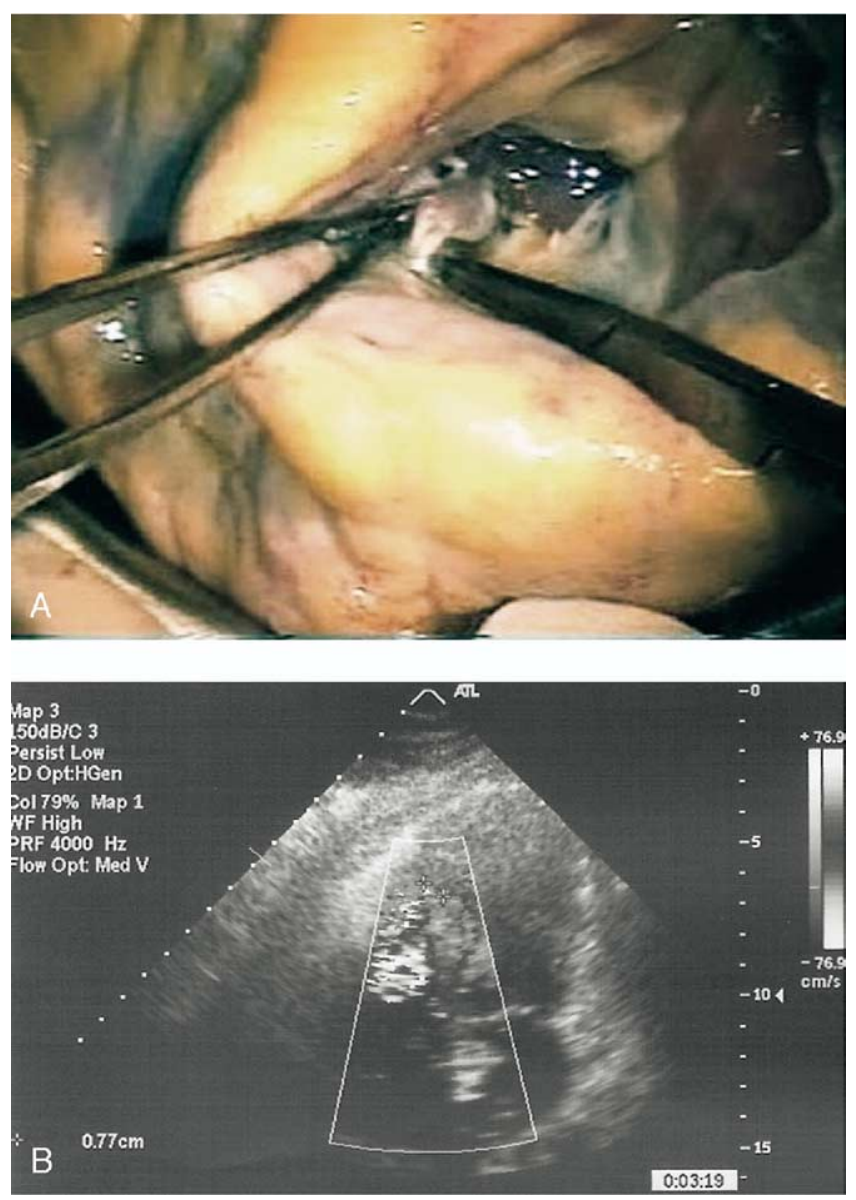

Figure 1. A, Operative photograph of perimembranous VSD. B, Echocardiogram.

tient was discharged after an uneventful postoperative course. A transthoracic echocardiogram performed 4 weeks after transplantation showed mild tricuspid insufficiency, with a mean pulmonary artery pressure of $35 \mathrm{~mm} \mathrm{Hg}$ and a small residual restrictive VSD. The patient had a favorable course and is in functional class I at 42 months' follow-up.

PATIENT 2. A 31-year-old woman was given a diagnosis of brain death after craniotomy, and consent was obtained for multiple organ donation.

The preharvesting transthoracic echocardiogram of the donor heart revealed an 8-mm restrictive perimembranous VSD (Figure
$1, B)$ with a left ventricular ejection fraction of $70 \%$ on $6 \mu \mathrm{g} \cdot \mathrm{kg}^{-1}$ - $\min ^{-1}$ norepinephrine.

A compatible 59-year-old male recipient with terminal idiopathic dilated cardiomyopathy was identified at our institution.

The donor heart was explanted as described before. The VSD was repaired through a right auricular approach with 2 interrupted polypropylene 4-0 sutures. A standard orthotopic heart transplantation (Stanford technique) was performed with an ischemic time of 96 minutes. The postoperative course was uneventful. An echocardiogram obtained after 2 weeks showed a mild, inferior, nonconstrictive pericardial effusion with no residual VSD. The patient had a favorable course and is in functional class I at 6 months' follow-up.

\section{Discussion}

We report 2 cases of surgical closure of VSD immediately before heart transplantation. Confronted with a limited supply, criteria for donor hearts are continuously expanding. ${ }^{1}$ Previous surgical repair of an atrial septal defect before transplantation has been reported. ${ }^{5}$ Previous studies have reported surgical or transcatheter closure of residual atrial septal defects distant from the transplantation. ${ }^{5}$

The goals of the procedure were to harvest the donor heart, correct the VSD, and proceed with the transplantation successfully within an acceptable amount of time. Surgical closure of the VSD before implantation in the recipient was done on the back table by using an auricular and ventricular approach, respectively. These repairs had no untoward functional consequences on the patient's outcome and recovery.

On the basis of this small experience, heart donation should be considered in the presence of a small VSD without compromise of right ventricular function. Appropriate selection will contribute to the enlargement of the pool of available donor organs.

\section{References}

1. Loebe M, Potapov EV, Hummel M, Weng Y, Bocksch W, Hetzer R. Medium-term results of heart transplantation using older donor organs. J Heart Lung Transplant. 2000;19:957-64.

2. Schulman LL, Smith CR, Drusin R, Rose EA, Enson Y, Reemtsma K. Patent foramen ovale complicating heart transplantation, a window on post transplantation hemodynamics. Chest. 1987;92:569-72.

3. Weston MW, Raghavendra V, Sastry NS. Closure of a patent foramen ovale and tricuspid valve replacement after heart transplantation. Ann Thorac Surg. 1996;61:717-9.

4. Laughlin MP, Bricker JT, Millins CE, Cabalka AE, Gelb BD, Towbin JA. Transcatheter closure of residual atrial septal defects following cardiac transplantation. Catheter Cardiovasc Diagn. 1993;28:162-3.

5. Loebe M, Koerner MM, Zener J, Lafuente JA, Torre-Amione G, Noon GP. Use of a donor heart that had undergone previous cardiac surgery for ASD closure. J Heart Lung Transplant. 2002;21:294-5. 